International Journal of Medical Arts 2020; 2 [3]: 655-660.

Available online at Journal Website
https://ijma.journals.ekb.eg/
Main subject [Medicine [Dermatology] ${ }^{*}$

Original article

\title{
Comparative Study between Sertraline and Omega-3 Supplementation in The Treatment of Uremic Pruritus in Hemodialysis Patient
}

Mohamed Fathy Elghareib[a], Ibrahim Fouda[a], Hassan Mohamed Khodair [a]; Ahmed Salama Al-Adl[b] Department of Dermatology, Damietta General Hospital, Ministry of Health, Egypt[a]

Department of Internal Medicine [Nephrology Unit], Damietta Faculty of Medicine, Al-Azhar University, Egypt[2]

Corresponding author

Moahmed Fathy Elghareib

Email: focus.fathey@gmail.com

Received at: May 27, 2020; Revised at: June 13, 2020; Accepted at: June 13, 2020; Available online at: June 13, 2020

DOI: 10.21608/ijma.2020.31065.1127

\section{ABSTRACT}

Background: Pruritus in uremic patients decreases the quality of life because of sleep disturbances, depression and anxiety, thus, pruritus remains an important health issue in ESRD patients.

Aim of the work: To evaluate the efficacy and safety of sertraline versus omega 3 supplementation in the treatment of uremic pruritus.

Patients and Methods: This randomized case control study was conducted on patients with ESRD patients .All studied subjects had been collected from the Al-Azhar hospital [Damietta] Dialysis Center. This study had been carried out on 50 patients divided into: Group $[\mathrm{A}]$ : consists of 25 patients had been received $50 \mathrm{mg}$ sertraline twice a day for 8 weeks. Group [B]: consists of 25 patients and had been receive 3 gm omega-3 daily.

Results: Although pruritus severity decrease significantly in both groups and both scoring systems $[P<0.001]$, the reduction was significantly more in sertraline group [ $p<0.001$ in VAS]. The mean pruritus score [VAS] in the omega- 3 group

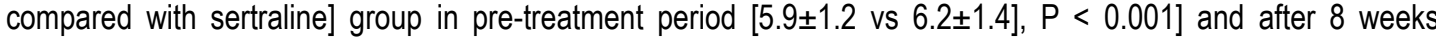
$[5.1 \pm 0.87$ vs. $4.7 \pm 1.02, P<0.001]$ intervention periods showed higher significant decrease in sertraline group.

Conclusion: Omega-3 fatty acids found to be effective in decreasing of uremic pruritus. So, it seems that Omega- 3 fatty acids could be used as an efficient drug for treatment of pruritus in uremic patients. The present study showed that lowdose sertraline was effective for antihistamine-refractory uremic pruritus than omeg3 in renal palliative care patients.

Keywords: Omega-3; Sertraline; Pruritus; End-stage Renal Disease; Uremic; Renal.

This is an open access article under the Creative Commons license [CC BY] [https://creativecommons.org/licenses/by/2.0/]

Please cite this article as: Elghareib MF, Fouda I, Khodair HM, Al-Adl AS. Comparative Study between Sertraline and Omega-3 Supplementation in The Treatment of Uremic Pruritus in Hemodialysis Patient. IJMA 2020; 2[3]: 655-660.

* Main subject and any subcategories have been classified according to research topic. 


\section{INTRODUCTION}

Chronic kidney disease [CKD] and its last stage, end stage renal disease [ESRD] are becoming the critical problem in a whole world [1]. Pruritus is an unpleasant feeling that occurs due to some systemic diseases such as ESRD [2]. It is the most common skin condition associated with ESRD. It affects up to $50 \%$ of the patients [3].

Although various treatments have been recommended to treat this symptom, the only definite treatment for these patients is kidney transplantation. Since most ESRD patients do not get the opportunity to receive kidney, performing studies to asses this unpleasant consequence is necessary [4].

Various mechanisms, such as xerosis, neuropathy, release of substance $P$, mast cell over activity, inflammation, immunological impairment, etc., were described as the pathogenesis of UP. Its' exact pathogenesis and treatment have not been fully understood yet. As a result, many studies were designed to find a treatment for this complication [5].

Pruritus in uremic patients decreases the quality of life because of sleep disturbances, depression and anxiety [6]. Thus, pruritus remains an important health issue in ESRD patients and it is important to explore an efficient treatment option for it.

Looking briefly at previous studies, it reveals that many medical and nonmedical treatments are used to relieve UP. Many chemical and herbal treatments such as antidepressants [Mirtazapine, paroxetine, and doxepin], anticonvulsants [Gabapentin, pregablin], opioids, ultraviolet B light [UVB], and recently turmeric are suggested to relieve ESRD related pruritus [5].

Some studies conducted to determine the effect of herbal medicine, such as turmeric and capsaicin on UP $[4,5]$.

Selective serotonin reuptake inhibitors [SSRI] such as paroxetine have been shown to be effective in systematic pruritus [2].

Sertraline is another SSRI that can be prescribed in ESRD patients without any dose adjustment; previous studies on sertraline assessed its effect on cholestatic pruritus more than uremic [7].

Dietary intake of these fatty acids is necessary because of limited enzymatic conversion of a-linoleic acid to EPA and DHA [8]. It is postulated that dietary fish intake is inadequate in dialysis patients due to the concerning lack of nutritional guidelines to encourage patients to consume fish and other seafood, Furthermore, fish oil has other benefits such as lowering blood pressure and reducing cholesterol, LDL, triglyceride amount which lowers the risk of atherosclerosis in hemodialysis patients[9].

\section{AIM OF THE WORK}

Evaluating the efficacy and safety of sertraline versus omega 3 supplementation in the treatment of uremic pruritus among hemodialysis patients.

\section{PATIENTS AND METHODS}

This randomized control study was conducted on 50 patients with ESRD patients. All studied patients had been collected from the Al-Azhar hospital [Damietta] Dialysis center. A written informed consent was taken from all patients in this study after informing them about the study that was approved from the Ethical Committee of Human Right in Research at the Al-Azhar University hospital [Damietta] Dialysis center. This study had been conducted on 40 subjects divided into: Group [A]: consists of 25patients had been received $50 \mathrm{mg}$ sertraline twice a day for 8 weeks. Group [B]: consists of 25 patients had been receive $3 \mathrm{gm}$ omega-3 daily.

Inclusion criteria: All adult patients [ $>18$ years] undergoing hemodialysis for at least 1 month complaining of pruritus for more than 8 weeks will include in the study

Exclusion criteria: Poor compliance, Current pruritus treatment, Skin lesions or other skin disorders, Malignancy, Patients who consumed emollients cream 2 weeks or antihistamine and gabapentin 1 month before study.

\section{Every individual in the study was subjected to the followings}

A. History taking: A preformed sheet was filled for all patients. It included [Personal, present illness, drug intake, systemic disease [e.g., diabetes mellitus, hypertension, etc...] and family history].

B- Full Clinical examination: General examination: General examination of systems to discover predisposing factors, associated medical 
conditions and to exclude chronic inflammation. Dermatological examination: Base on detailed analysis following Visual analogue scale [VAS], a most common scale that used in itching, is a $10 \mathrm{~cm}$ long vertical or horizontal line ranging from 0 [no symptom] to 10 [most severe pruritus] point will propose: $0=$ no pruritus, $>0-<4$ points $=$ mild pruritus, $\geq 4-<7$ points $=$ moderate pruritus, $\geq 7-<$ 9 points $=$ severe pruritus, and $\geq 9$ points $=$ very severe pruritus, the VAS is a valuable method of pruritus measurement.

C] - Ethical consideration: Informed consent was obtained from all patients after being informed about the aims and process of the study as well as applicable objectives.

The study procedures were free from any harmful effects on the patients as well as the service provided and The principal investigators have kept individual data as private information safely. There was no extra fee to be paid by the patients and the investigators covered all the costs in this regard.

Data management and Statistical Analysis: Data entry, processing and statistical analysis was carried out using MedCalc ver. 18.2.1 [MedCalc, Ostend, Belgium]. Tests of significance [KruskalWallis, Wilcoxon's, Chi square, logistic regression analysis, and Spearman's correlation] were used. Data were presented and suitable analysis was done according to the type of data [parametric and nonparametric] obtained for each variable. P-values less than $0.05[5 \%]$ was considered to be statistically significant
There was no significant difference between groups regarding age. The mean $\pm S D$ ages of group $A, B$ were $[57.9 \pm 12.3]$ years and $58.1 \pm 10.6]$ years, respectively. Also, there was no significant difference between groups regarding sex [Table 1]

Table [2] showed that, there was no significant difference between groups regarding etiology.

Table [3] showed the distribution of the studied patients regarding their duration of dialysis; the mean duration of dialysis for the studied group $A$ was $37.9 \pm 14.7$ months and group $B$ was $39.4 \pm 17.2$, with no significant difference between groups.

Table [4] revealed that, both groups were comparable as regard to itching nature, associated lesions and xerosis.

Table [5] showed the distribution of the studied patients regarding their mean of pruritus score differences before and after 8 weeks of omega- 3 and sertraline intervention. The initial average of VAS scoring system was $6.2 \pm 1$.4and group $B$ was $5.9 \pm 1.2$ with no significant difference between groups. Although pruritus severity decreases significantly in both groups and both scoring systems $[P<0.001]$, the reduction was significantly more in sertraline group [ $<<0.001$ in VAS]. The mean pruritus score [VAS] in the omega-3 group compared with sertraline] group in pre-treatment period [5.9 \pm 1.2 vs $6.2 \pm 1.4], P<0.001]$ and after 8 weeks $[5.1 \pm 0.87$ vs. $4.7 \pm 1.02, P<0.001]$ intervention periods showed higher significant decrease in sertraline group.

\section{RESULTS}

Table [1]: Demographic and baseline clinical characteristics of the study groups

\begin{tabular}{|c|c|c|c|c|}
\hline Demographic data & $\begin{array}{l}\text { Group A } \\
{[n=25]}\end{array}$ & $\begin{array}{c}\text { Group B } \\
{[n=25]}\end{array}$ & t- test & $P$ value \\
\hline Age [years] & $57.9 \pm 12.3$ & $58.1 \pm 10.6$ & 0.107 & 0.915 \\
\hline 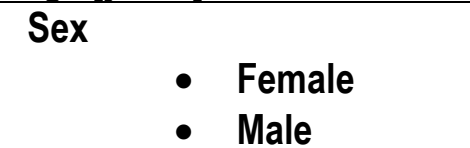 & $\begin{array}{l}15[60 \%] \\
10[40 \%]\end{array}$ & $\begin{array}{l}14[56 \%] \\
11[44 \%]\end{array}$ & 0.89 & 0.282 \\
\hline
\end{tabular}

Table [2]: The distribution of Etiology in the studied group

\begin{tabular}{|l|c|c|c|}
\hline \multicolumn{1}{|c|}{ Etiology } & $\begin{array}{c}\text { Group A } \\
{[\mathbf{n = 2 5 ]}}\end{array}$ & $\begin{array}{c}\text { Group B } \\
{[\mathbf{n = 2 5}]}\end{array}$ & p-value \\
\hline Diabetic nephropathy & $10[40 \%]$ & $11[44 \%]$ & \multirow{2}{*}{$\mathbf{0}$} \\
\hline Hypertensive nephropathy & $11[44 \%]$ & $13[52 \%]$ & \\
\hline Others & $4[16 \%]$ & $1[4 \%]$ & \\
\hline
\end{tabular}


Table [3]: Distribution of the studied patients regarding their duration of dialysis

\begin{tabular}{|c|c|c|c|}
\hline & $\begin{array}{c}\text { Group A } \\
{[\mathrm{n}=25]}\end{array}$ & $\begin{array}{c}\text { Group B } \\
{[\mathrm{n=25]}}\end{array}$ & p-value \\
\hline $\begin{array}{c}\text { Duration of } \\
\text { dialysis[months] }\end{array}$ & $37.9 \pm 14.7$ & $39.4 \pm 17.2$ & 0.974 \\
\hline
\end{tabular}

Table [4]: Itching type and associated lesions among the studied patients

\begin{tabular}{|c|l|c|c|c|}
\hline & & $\begin{array}{c}\text { Group A } \\
{[\mathbf{n = 2 5 ]}}\end{array}$ & $\begin{array}{c}\text { Group B } \\
{[\mathbf{n = 2 5 ]}}\end{array}$ & p-value \\
\hline Itching nature & Non specific & $23[92 \%]$ & $24[96 \%]$ & \\
& Burning sensation & $1[4]$ & $1[4]$ & 0.641 \\
& Tingling & $1[4]$ & $0[0]$ & \\
\hline Associated lesions & Yes & $20[80]$ & $18[72]$ & 0.792 \\
& No & $5[20]$ & $7[28]$ & \\
\hline Xerosis & No & $5[20]$ & $6[24]$ & 0.851 \\
& Yes & $20[80]$ & $19[76]$ & \\
\hline
\end{tabular}

Table [5]: The mean of pruritus score differences after 8 weeks of omega- 3 and sertraline treatment

\begin{tabular}{|c|c|c|c|}
\hline & \multicolumn{2}{|c|}{ pruritus score differences after 8 weeks } & \\
\hline & Pre treatment & After 8 weeks & p-value \\
\hline Group A [Sertraline] & $6.2 \pm 1.4$ & $4.7 \pm 1.02$ & $<0.001^{*}$ \\
Group B [Omega-3] & $5.9 \pm 1.2$ & $5.1 \pm 0.87$ & $0.001^{*}$ \\
\hline p value & $0.001^{*}$ & $0.001^{*}$ & \\
\hline
\end{tabular}

\section{DISUCSSION}

The present study showed that low-dose sertraline was effective for antihistamine-refractory uremic pruritus than omega3 in renal palliative care patients, as the main objective of our study was to compare sertraline versus omega3 in the treatment of pruritus in hemodialysis patients.

Our results are in agreement with study of Gharekhani et al.[11] as they reported that there was no statistically significant difference between groups regarding age and sex.

Pruritus often constitutes a major problem for patients with end-stage renal disease [ESRD]. Unfortunately, dialysis has only a slight improving impact on pruritus. Therefore, it is quite frustrating that an ever-increasing number of patients on hemodialysis, waiting for transplantation, suffer from this tormenting symptom for a long time. According to most sources, more than half of patients undergoing hemodialysis complain of varying degrees of pruritus [12].

The present study shows that there was no significant difference between groups regarding duration of uremic pruritus [HD related] with an average duration $\pm S D$ of $5.2 \pm 1.8$ years. Our results are in line with study of Pakfetrat et al. [5], as they reported that there was no statistically significant difference between groups regarding age and sex or duration of pruritus.

Our results are supported by study of Ghanei et al.[13] as they reported that there was no significant difference between groups regarding the duration of dialysis. The dialysis duration varied from 1 year to 17 years.

Visual analogue score [VAS] seems to be a valuable method of pruritus assessment. Using VAS various levels of pruritus can be defined, similarly to VRS, but, in addition, better discrimination of pruritus severity can be carried out, a property that makes this scale highly suitable for clinical studies evaluating various antipruritic regimens [14].

Although pruritus severity decreases significantly in both groups and both scoring systems $[P<0.001]$, the reduction was significantly more in sertraline group [ $p<0.001$ in VAS]. The mean pruritus score [VAS] in the omega-3 group compared with sertraline] group in pre-treatment period [5.9 \pm 1.2 vs $6.2 \pm 1.4], P<0.001]$ and after 8 weeks [5.1 \pm 0.87 vs. $4.7 \pm 1.02, P<0.001$ ] intervention periods showed 
higher significant decrease in sertraline group. Our results are supported by study of Ghanei et al.[13] as they reported that there was statistically significant difference among both groups regarding mean pruritic score. The treatment with omega-3 reduced the pruritus in up to $65 \%$ from mean score of 20.3 [95\% Cl: $16.7-23.8$ ] to 6.4 [95\% Cl: $2.9-9.8$ ].

Fallahzadeh et al.,[15] showed that serum levels of IL-2 were significantly higher in HD patients with itch in comparing with those without it. In the other hand, the Th1 effector cell proliferative response to antigen was decreased in the fish oil group and fish oil can mitigate the effect of interleukin 2. So, it can be considered as another mechanism for fish oil [16].

Furthermore, Pakfetrat et al.[5] found that patients who received sertraline showed more decrease in pruritus severity in both VAS and DUO scoring systems. Shakiba et al.[7] reported a significant decrease in pruritus intensity in DUO scoring system after sertraline consumption.

Makhlough et al. ${ }^{[4]}$ observed that there was no significant difference in pruritus scores before the treatment between the two groups, but after each week, the difference was significant $[P<0.001]$. Repeated measurement test showed that decreasing in pruritus severity in the capsaicin group was more than that in the placebo group during treatment period $[\mathrm{P}<.001]$.

In contrary to mentioned studies, Hajhashemi et al.[17] reported that, sertraline usually potentiated inflammation. Bot et al.[18] worked on CHD patients with depression that consumed sertraline for 10 weeks. They found no significant change in IL6, TNFa, and CRP of the case group.

Sertraline have some priorities to other drugs. Previous studies revealed that patients with moderate to severe pruritus were more susceptible for developing depression while the main role of sertraline is its antidepressant effect. Also, physician can prescribe sertraline for ESRD patients without any dose adjustment [2].

In conclusion, Omega-3 fatty acids found to be effective in decreasing of uremic pruritus. So, it seems that Omega-3 fatty acids could be used as an efficient drug for treatment of pruritus in uremic patients. The present study showed that low-dose sertraline was effective for antihistamine-refractory uremic pruritus than omega3 in renal palliative care patients. Further placebo-blinded randomized controlled studies are warranted to clarify our findings.

\section{Financial and Non-Financial Relationships and Activities of Interest}

None

\section{REFERENCES}

1. Khajehdehi P, Malekmakan L, Pakfetrat M, Roozbeh J, Sayadi M. Prevalence of chronic kidney disease and its contributing risk factors in southern Iran: a crosssectional adult population-based study. Iran J Kidney Dis. 2014 Mar;8[2]:109-15. [PMID: 24685733].

2. Chan KY, Li CW, Wong H, Yip T, Chan ML, Cheng HW, Sham MK. Use of sertraline for antihistamine-refractory uremic pruritus in renal palliative care patients. J Palliat Med. 2013 Aug;16(8):966-70. [DOI: 10.1089/jpm. 2012. 0504].

3. Attia EA, Hassan SI, Youssef NM. Cutaneous disorders in uremic patients on hemodialysis: an Egyptian casecontrolled study. Int J Dermatol. 2010 Sep;49(9):1024-30. [DOI: 10.1111/j.1365-4632.2010. 04466.x].

4. Makhlough A, Ala S, Haj-Heydari Z, Kashi Z, Bari A. Topical capsaicin therapy for uremic pruritus in patients on hemodialysis. Iran J Kidney Dis. 2010 Apr;4(2):13740. [PMID: 20404425].

5. Pakfetrat M, Basiri F, Malekmakan L, Roozbeh J. Effects of turmeric on uremic pruritus in end stage renal disease patients: a double-blind randomized clinical trial. J Nephrol. 2014 Apr;27(2):203-7. [DOI: 10.1007/s40620014-0039-2].

6. Mathur VS, Lindberg J, Germain M, Block G, Tumlin J, Smith M, Grewal M, McGuire D; ITCH National Registry Investigators. A longitudinal study of uremic pruritus in hemodialysis patients. Clin J Am Soc Nephrol. 2010 Aug;5(8):1410-9. [DOI: 10.2215/CJN.00100110].

7. Shakiba M, Sanadgol H, Azmoude HR, Mashhadi MA, Sharifi $H$. Effect of sertraline on uremic pruritus improvement in ESRD patients. Int J Nephrol. 2012; 2012: 363901. [DOI: 10.1155/2012/363901].

8. Riediger ND, Othman RA, Suh M, Moghadasian MH. A systemic review of the roles of $n-3$ fatty acids in health and disease. J Am Diet Assoc. 2009 Apr;109(4):668-79. [DOI: 10.1016/j.jada.2008.12.022].

9. Saglimbene VM, Wong G, van Zwieten A, Palmer SC, Ruospo M, Natale $P$, et al. Effects of omega-3 polyunsaturated fatty acid intake in patients with chronic kidney disease: Systematic review and meta-analysis of randomized controlled trials. Clin Nutr. 2020 Feb;39(2):358-368. [DOI: 10.1016/j.clnu.2019.02.041].

10. Daud ZA, Tubie B, Adams J, Quainton T, Osia R, Tubie $\mathbf{S}$, et al. Effects of protein and omega-3 supplementation, provided during regular dialysis 
sessions, on nutritional and inflammatory indices in hemodialysis patients. Vasc Health Risk Manag. 2012; 8: 187-95. [DOI: 10.2147/VHRM.S28739].

11. Gharekhani A, Khatami MR, Dashti-Khavidaki S, Razeghi E, Abdollahi A, Hashemi-Nazari SS, Mansournia MA. Effects of oral supplementation with omega-3 fatty acids on nutritional state and inflammatory markers in maintenance hemodialysis patients. J Ren Nutr. 2014 May;24(3):177-85. [DOI: 10.1053/j.jrn.2014. 01. 014].

12. Akhyani M, Ganji MR, Samadi N, Khamesan B, Daneshpazhooh M. Pruritus in hemodialysis patients. BMC Dermatol. 2005; 5:7 [DOI: 10.1186/1471-5945-5-7].

13. Ghanei E, Zeinali J, Borghei M, Homayouni M. Efficacy of omega-3 fatty acids supplementation in treatment of uremic pruritus in hemodialysis patients: a double-blind randomized controlled trial. Iran Red Crescent Med J. 2012 Sep;14(9):515-22. [PMID: 23115713]

14. Reich A, Heisig M, Phan NQ, Taneda K, Takamori K, Takeuchi S, et al. Visual analogue scale: evaluation of the instrument for the assessment of pruritus. Acta Derm Venereol. 2012 Sep; 92(5):497-501. [DOI: 10.2340/ 00015555-1265].
15. Fallahzadeh MK, Roozbeh J, Geramizadeh B, Namazi MR. Interleukin-2 serum levels are elevated in patients with uremic pruritus: a novel finding with practical implications. Nephrol Dial Transplant. 2011 Oct;26 (10): 3338-44. [DOI: 10.1093/ndt/gfr053]

16. Zhang P, Kim W, Zhou L, Wang N, Ly LH, McMurray DN, Chapkin RS. Dietary fish oil inhibits antigen-specific murine Th1 cell development by suppression of clonal expansion. J Nutr. 2006 Sep;136(9):2391-8. [DOI: 10. 1093/ jn/136.9.2391]

17. Hajhashemi V, Minaiyan M, Eftekhari M. AntiInflammatory activity of a selection of antidepressant drugs. Iran J Pharm Sci. 2008; 4:225-230.

18. Bot M, Carney RM, Freedland KE, Rubin EH, Rich MW, Steinmeyer BC, Mann DL. Inflammation and treatment response to sertraline in patients with coronary heart disease and comorbid major depression. J Psychosom Res. 2011 Jul;71(1):13-7. [DOI: 10.1016/j.jpsychores. 2010.11.006] 